Article

\title{
Decorating MOF-Derived Nanoporous Co/C in Chain-Like Polypyrrole (PPy) Aerogel: A Lightweight Material with Excellent Electromagnetic Absorption
}

\author{
Xiaodong Sun ${ }^{1}$, Xuliang $\mathrm{Lv}^{1}$, Mingxu Sui ${ }^{1}$, Xiaodi Weng ${ }^{2}$, Xiaopeng $\mathrm{Li}^{3, *}$ and Jijun Wang ${ }^{4, *}$ \\ 1 Key Laboratory of Science and Technology on Electromagnetic Environmental Effects and Electro-Optical \\ Engineering, The Army Engineering University of PLA, Nanjing 210007, China; \\ xiaodongsun1001@hotmail.com (X.S.); xllu1957@126.com (X.L.); plasmx@126.com (M.S.) \\ 2 PLA Rocket Force Research Institute, Beijing 100011, China; fefebi@163.com \\ 3 School of Information and Communications, National University of Defense Technology, Xi'an 710106, China \\ 4 Research Institute for National Defense Engineering of Academy of Military Science PLA China, \\ Beijing 100036, China \\ * Correspondence: asmany@163.com (X.L.); greenant77@sina.com (J.W.)
}

Received: 12 April 2018; Accepted: 9 May 2018; Published: 11 May 2018

\begin{abstract}
To clear away the harmful effects of the increment of electromagnetic pollution, high performance absorbers with appropriate impedance matching and strong attenuation capacity are strongly desired. In this study, a chain-like PPy aerogel decorated with MOF-derived nanoporous $\mathrm{Co} / \mathrm{C}$ (Co/C@PPy) has been successfully prepared by a self-assembled polymerization method. With a filler loading ratio of $10 \mathrm{wt} \%$, the composite of Co/C@PPy could achieve a promising electromagnetic absorption performance both in intensity and bandwidth. An optimal reflection loss value of $-44.76 \mathrm{~dB}$ is achieved, and the effective bandwidth (reflection loss lower than $-10 \mathrm{~dB}$ ) is as large as $6.56 \mathrm{GHz}$. Furthermore, a composite only loaded with $5 \mathrm{wt} \% \mathrm{Co} / \mathrm{C} @ P$ Py also achieves an effective bandwidth of $5.20 \mathrm{GHz}$, which is even better than numerous reported electromagnetic absorption (EA) materials. The result reveals that the as-fabricated Co/C@PPy—with high absorption intensity, broad bandwidth, and light weight properties—can be utilized as a competitive absorber.
\end{abstract}

Keywords: zeolite imidazole framework; electromagnetic absorption; interfacial polarization; heterostructure

\section{Introduction}

The utilization of electromagnetic waves has been expanded extensively in both civilian and military fields, yet it generates potential hazards on the performance of sophisticated electronic devices and biological immune systems of human beings and wildlife [1-4]. Tremendous efforts have been devoted in recent decades toward investigating suitable electromagnetic absorption (EA) materials to eliminate or at least decrease these ensuing problems [5-7].

Traditional absorbers are mainly composed of ferromagnetic metals [8], carbon [9], and conducting polymers materials [10]. However, ferromagnetic metals are susceptible to corrosion, and are high density with insufficient bandwidth [11]; the high conductivity of the pure carbon and conducting polymers materials always induce an eddy current effect and reflection [12]. In general, the attenuation capacity and the complementarity between the complex permittivity and complex permeability (namely, impedance matching) are two crucial factors in the design of outstanding absorbers [13-15]. Some requirements including wide effective bandwidth (reflection loss lower than $-10 \mathrm{~dB}$ ), being lightweight, and low thickness should also be satisfied [16-18]. Specifically, the development of functional dielectric materials modified with other composites can represent a significant advance to improve EA performance both in intensity and width. Taking polypyrrole (PPy) as an example, it is 
a type of the intrinsically conducting polymers which has been investigated as a permittivity regulation for EA materials mainly result from its dielectric property $[19,20]$. Furthermore, the lightweight of PPy aerogel after drying out the solvent which also matches the feature of high-performance absorbers. So far, substantial efforts have been devoted to exploiting PPy based materials for EA advances and the exhibited performances are highly desirable, such as $\mathrm{Fe}_{3} \mathrm{O}_{4} / \mathrm{PPy} / \mathrm{PANI}$ [21], $\mathrm{PPy} / \mathrm{RGO}$ (reduced graphene oxide) [12], CIP (carbonyl iron powder)@PPy [22], $\gamma-\mathrm{Fe}_{2} \mathrm{O}_{3} / \mathrm{PPy}$ [23], and PPy/SiC [24].

Apart from the aforementioned absorbers, recently, metal-organic frameworks (MOFs) have been the focus of intense research due to their wide spectrum of useful characteristics [25-28]. The structure of MOFs is comprised of metal ions or clusters that are connected by electron-donating "linker" groups to create a networked structure with well-defined pores [29-31]. In the past few years, MOFs have been intensively used as excellent carbon precursors to synthesize nanoporous carbon materials via direct carbonization without using auxiliary templates [32]. Especially, the previous reports suggested that Co/C composites (the resultant of a typical zeolite imidazole framework, ZIF-67 [Co(2-methylimidazole $\left.)_{2}\right]$ ) or their hybrids have significant potential for a lightweight EA material due to their increased permittivity and high porosity [33]. For example, Liang and coworkers obtained selectively nanoporous carbon materials consisting of ZnO/NPC@Co/NPC as the shells by the thermal treatment of ZIF-8@ZIF-67 crystals [26]. The composite ZnO/NPC@Co/NPC-0.5 sample filling with $50 \mathrm{wt} \%$ of paraffin shows a maximum reflection loss (RL) of $-28.8 \mathrm{~dB}$ at a thickness of $1.9 \mathrm{~mm}$. A functionalized Co/C composite has also been synthesized by Qiang et al. via in situ pyrolysis of ZIF-67 [34]. Under the optimum conditions, Co/C-800 as the best candidate displays excellent EA property, which the minimum RL can even reach up to $-39.6 \mathrm{~dB}$ at a thickness of $2.0 \mathrm{~mm}$. It is expected that impedance matching degree and attenuation capability can be adjusted simultaneously by the combination of the $\mathrm{Co} / \mathrm{C}$ composites and other absorbers. Note that neither extremely high nor low permittivity can promote the formation of high-performance absorber, and it is crucial to take both impedance matching and attenuation capacity into account. Herein, a chain-like PPy aerogel decorated with MOF-derived nanoporous Co/C (Co/C@PPy) has been successfully prepared by a self-assembled polymerization method. We hope that the combination of these components could result an appropriate permittivity value, thus lead a high EA performance simultaneously. The approach is quite facile (only several minutes) and convenient for mass production. Taking advantage of the heterostructure constructed by ternary components, a proper match behavior and the induced intensified interfacial polarization have been achieved. To best of our knowledge, such material has rarely been reported to date. As a result, this hybrid aerogel exhibits the feature of lightweight, wide effective EA bandwidth and strong attenuation capacity with an extremely low filler loading ratio simultaneously, which meets the standards of an absorber. From this view, the Co/C@PPy aerogel fabricated in our work is promising for practical applications as a high-performance absorber.

\section{Materials and Methods}

\subsection{Materials}

All regents were of analytical grade and used without further purification. Cobalt nitrate hexahydrate $\left(\mathrm{Co}\left(\mathrm{NO}_{3}\right)_{2} \cdot 6 \mathrm{H}_{2} \mathrm{O}\right)$, ferric chloride $\left(\mathrm{FeCl}_{3} \cdot 6 \mathrm{H}_{2} \mathrm{O}\right)$, 2-methylimidazole (mIM), methanol, ethanol, and the pyrrole monomer were purchased from GENERAL-REAGENT, Titan Scientific Co., Ltd., Shanghai, China. Deionized water was obtained from Direct-Q3 UV, Millipore (Burlington, MA, USA).

\subsection{Synthesis of Nanoporous Co/C Composites}

Porous Co/C composites were prepared by the calcination of ZIF-67 polyhedron precursors under Ar. ZIF-67 polyhedron were prepared by the simple precipitation as reported previously [34]. In a typical procedure, $0.6 \mathrm{~g} \mathrm{Co}\left(\mathrm{NO}_{3}\right)_{2} \cdot 6 \mathrm{H}_{2} \mathrm{O}$ and $0.8 \mathrm{~g}$ mIM dissolved in a methanol solution (55 $\left.\mathrm{mL}\right)$ to generate a purple suspension at room temperature. After vigorous magnetic stirring for $6 \mathrm{~h}$, 
the resulting solution was aged for another $24 \mathrm{~h}$ and then centrifuged, rinsed with methanol, and dried at $45^{\circ} \mathrm{C}$ for $12 \mathrm{~h}$. To convert ZIF-67 to nanoporous Co/C nanoparticles, the as-fabricated ZIF-67 was transferred to a combustion boat and heated at a rate of $2^{\circ} \mathrm{C} \cdot \mathrm{min}^{-1}$ and maintained at $600{ }^{\circ} \mathrm{C}$ for $6 \mathrm{~h}$.

\subsection{Synthesis of Synthesis of Co/C@PPy Aerogel}

Briefly, $135.0 \mathrm{mg}$ pyrrole monomer and $12.0 \mathrm{mg} \mathrm{Co} / \mathrm{C}$ nanoparticles were slowly dissolved in a mixture containing $2.0 \mathrm{~mL}$ deionized water and $2.0 \mathrm{~mL}$ absolute ethanol. Then $1.6 \mathrm{~g} \mathrm{FeCl} \cdot 6 \mathrm{H}_{2} \mathrm{O}$ ultrasonically dispersed in $1.0 \mathrm{~mL}$ deionized water and $1.0 \mathrm{~mL}$ absolute ethanol was stepwise injected into the above solution under mechanical stirring for $5 \mathrm{~min}$ and the hydrogel was obtained by aging for $24 \mathrm{~h}$. The precipitate was filtered, washed, and dialyzed several times with deionized water and ethanol to wipe out impurities, and then dried at $50{ }^{\circ} \mathrm{C}$ for $12 \mathrm{~h}$ to form an aerogel.

\subsection{Characterization and Measurement}

The structural analyses of the composites prepared in this work were obtained by X-ray diffraction (XRD) using a X-ray diffraction (D8-Advance, Bruker, Germany) equipped with $\mathrm{Cu}-\mathrm{K} \alpha$ radiation (1.5406 А). The morphology, size distribution and shape of the composites were observed with a transmission electron microscope (TEM), high resolution TEM (HRTEM) by using a field emission TEM (JEM-2100F, JEOL, Tokyo, Japan) and scanning electron microscope (SEM) by using a field emission scanning electron microscope (FE-SEM, S4800, Hitachi, Tokyo, Japan). Raman spectroscopy was carried out via Raman microscope (Renishaw, London, UK) equipped with an excitation line of $532 \mathrm{~nm}$. X-ray photoelectron spectra (XPS) were recorded using a ESCALAB 250Xi X-ray photoelectron spectrometer (Thermo Fisher Scientific, Waltham, MA, USA) equipped with a monochromatic Al $\mathrm{K} \alpha \mathrm{X}$-ray source $(1486.6 \mathrm{eV})$. The thermogravimetric analysis were carried out on a SDT Q600 TGA (TA Instruments, Newcastle, DE, USA). The details on the electromagnetic measurements of the samples have been described elsewhere. The complex relative permeability $\left(\mu_{r}=\mu^{\prime}-j \mu^{\prime \prime}\right)$ and permittivity $\left(\varepsilon_{r}=\varepsilon^{\prime}-j \varepsilon^{\prime \prime}\right)$ were calculated from the S-parameters tested by a vector network analyzer (VNA, N5242A PNA-X, Agilent, Agilent Technologies Inc., Santa Clara, CA, USA). The theoretical reflection loss (RL) can be calculated based on the $\varepsilon_{r}$ and $\mu_{r}$ at a given frequency and layer thickness by means of the equations [35-37]

$$
\begin{gathered}
\mathrm{RL}=20 \log \left|\left(Z_{i n}-Z_{0}\right) /\left(Z_{\text {in }}+Z_{0}\right)\right| \\
Z_{i n}=Z_{0} \sqrt{\frac{\mu_{r}}{\varepsilon_{r}}} \tanh \left(j \frac{2 \pi f d \sqrt{\mu_{r} \varepsilon_{r}}}{c}\right)
\end{gathered}
$$

where $Z_{\text {in }}$ is the input characteristic impedance, $c$ is the velocity of light in vacuum, $f$ is the frequency of the incident wave, $d$ is the thickness of the composites, $Z_{0}=376.7 \Omega$ is the intrinsic impedance of free space. In general, materials with RL value of less than $-10 \mathrm{~dB}$ (comparable to $90 \%$ attenuation) are considered as suitable absorbers.

\section{Results and Discussion}

\subsection{Characterization of Samples}

Figure 1 discusses the schematic representation for the formation of Co/C@PPy. In brief, via a process of oxidation polymerization, $\mathrm{Co} / \mathrm{C}$ nanoparticles are uniformly embedded in a three-dimensional network structure constructed by PPy chains. With a sufficient filler loading of Co/C@PPy, the conductive network can be formed spontaneously. When the incident electromagnetic wave gets into such network, the electromagnetic wave energy is transferred in the form of microcurrent and consumed. In this work, not only the multiple reflection in the matrix but also the interfacial polarization induced by the interfaces between Co, C, PPy, paraffin matrix and air bubbles play a significant role in enhancing the EA property. 
XRD results are investigated to ascertain the constituents of the ZIF-67, Co/C, and Co/C@PPy, and the spectra are presented in Figure 2 and Figure S1. The positions of the diffraction peaks of the obtained ZIF-67 corresponded to the XRD pattern simulated from the single crystal data of ZIF-67 [34]. As for $\mathrm{Co} / \mathrm{C}$ in Figure $2 \mathrm{~b}$, the main peaks observed at $2 \theta$ values of $44.5^{\circ}, 51.3^{\circ}$, and $75.9^{\circ}$ can attributed to (111), (200), and (220) planes of metallic Co according to JCPDS No. 89-4307. Some weak diffraction peaks of $37.7^{\circ}, 42.6^{\circ}, 62.2^{\circ}, 74.2^{\circ}$, and $78.1^{\circ}$ (labeled as "\$") assigned to CoO (JCPDS no. 75-0393) and the corresponding crystal planes are (111), (200), (311), (222). The existence of CoO can be attributed to the exposure of small amount of Co particles to air. Because Co is a moderately reactive element, the deposited Co nanoparticles can be slowly oxidized [25]. In addition, the absence of corresponding diffraction sharp peak for graphite at around $26^{\circ}$ suggests the homogeneous dispersion on the surface of the nanoporous $\mathrm{Co} / \mathrm{C}$ composites [38]. PPy shows an amorphous structure since the broad XRD pattern is around 20 to $30^{\circ}$ (Figure S1) [20]. Raman spectroscopy is well known as a powerful tool for the characterization of graphite based materials. In Figure 2c, the Raman spectra of $\mathrm{Co} / \mathrm{C}$ composite is associated with a typical D band and $G$ band at around $1338 \mathrm{~cm}^{-1}$ and $1579 \mathrm{~cm}^{-1}$, respectively. The D band becomes active in perfect graphite, which corresponds to the breathing mode of k-point photons of $A_{1 g}$ symmetry, and the $G$ band is ascribed to the vibration of $\mathrm{sp}^{2}$ carbon atoms [39]. The intensity ratio of $D$ band and $G$ band $\left(I_{D} / I_{G}\right)$ is a criterion to evaluate the graphitization degree of graphitic materials [40]. In this situation, the value of $I_{D} / I_{G}$ is 1.1 for $C o / C$, and such high value is mainly derived from the lower graphitization degree, which is near identical to the broad and weak diffraction peaks at around $26^{\circ}$ in the XRD pattern.

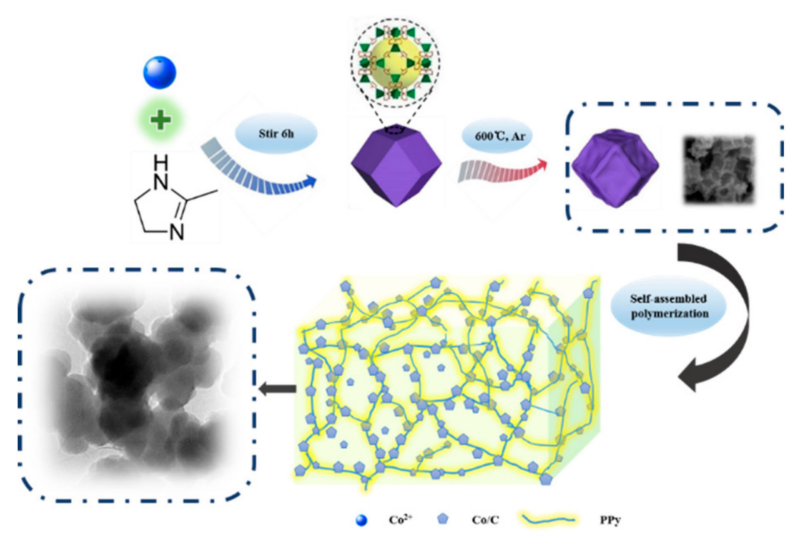

Figure 1. Schematic representation of the formation of Co/C@PPy aerogel.
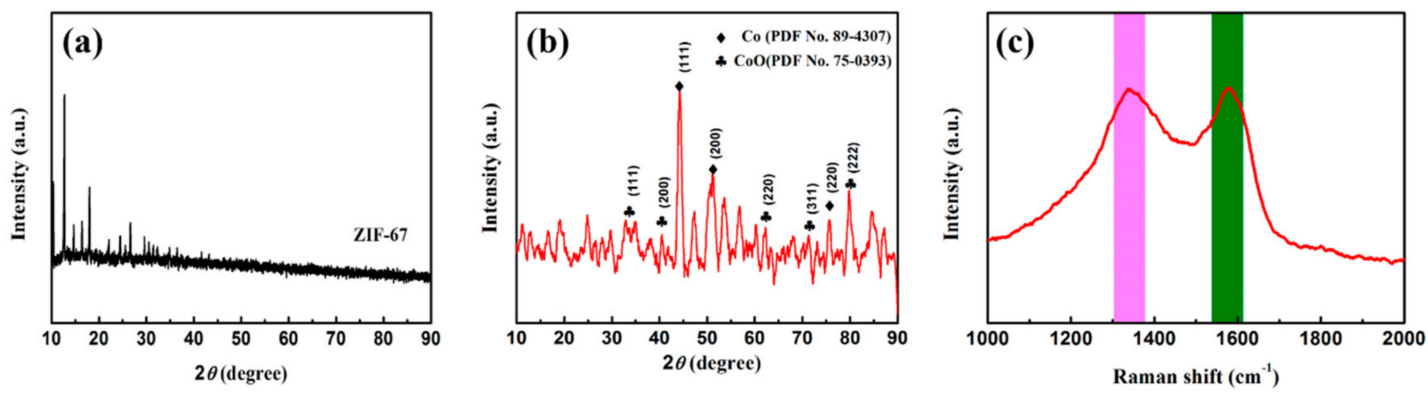

Figure 2. XRD patterns of ZIF-67 (a); Co/C (b) and Raman spectra of Co/C (c).

Surface elemental chemical states are confirmed by XPS measurement and the results are shown in Figure 3. In Figure 3a The $C$ 1s peaks can be resolved into five rational Gaussian peaks at 283.55, 284.61, $285.86,287.05$, and $288.31 \mathrm{eV}$, which can be assigned to the structures of $\mathrm{N}-\mathrm{C}=\mathrm{C}, \mathrm{C}-\mathrm{C}=\mathrm{C}, \mathrm{C}-\mathrm{C}-\mathrm{N}, \mathrm{C}-\mathrm{O}$, and $\mathrm{O}-\mathrm{C}=\mathrm{O}$, indicating the existence of carbonyl defects in PPy [19]. The $\mathrm{N}$ 1s peaks presented in Figure $3 \mathrm{~b}$ is decomposed into three Gaussian peaks with $401.55,399.45$, and $397.70 \mathrm{eV}$, respectively, 
which are corresponded to positively charged nitrogen atoms $\left(\mathrm{NH}^{+}\right)$, secondary amine-like structure $(\mathrm{N}-\mathrm{H})$, and imine-like structure $(\mathrm{C}=\mathrm{N})$ of pyrrole ring. Besides, SEM characterization of the fracture section of the Co/C@PPy and corresponding elemental mappings of $\mathrm{C}, \mathrm{O}, \mathrm{N}$, and Co are displayed in Figure 4. It is demonstrated that Co nanoparticles possess a relatively uniform distribution in the carbon matrix.
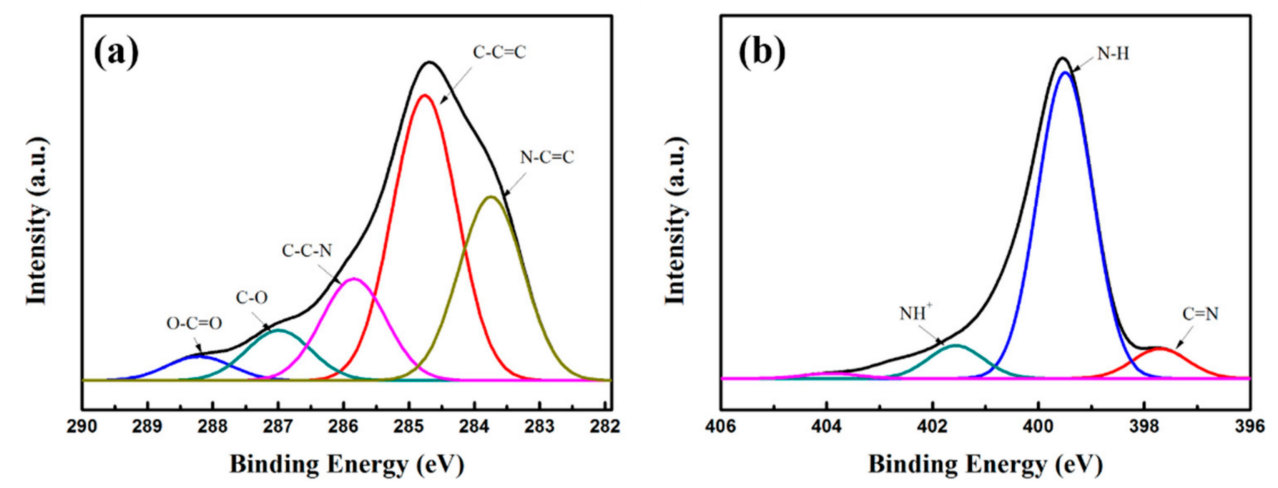

Figure 3. XPS spectra of Co/C@PPy: (a) N 1s; (b) C 1s.

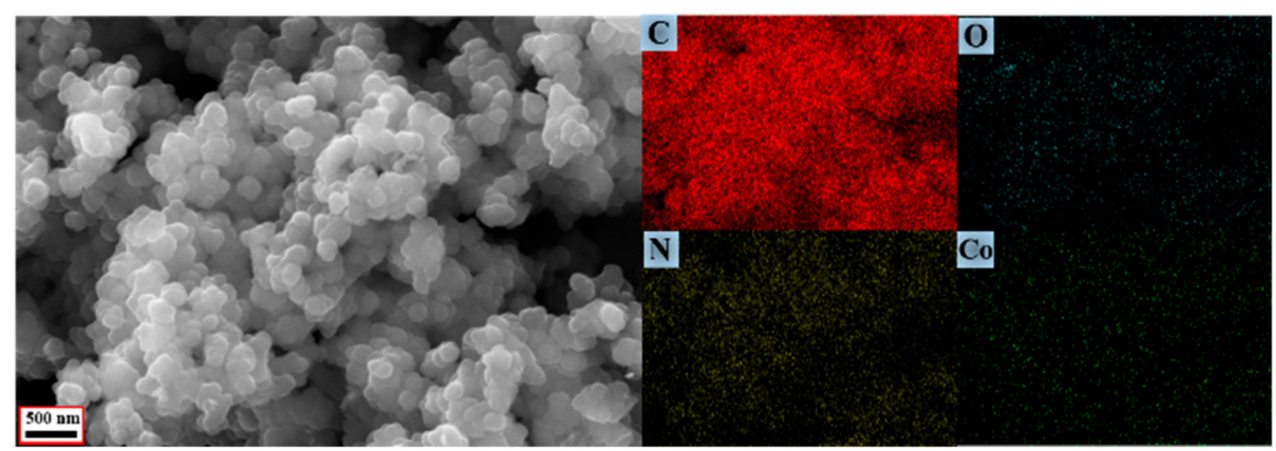

Figure 4. SEM image of the fracture section of the Co/C@PPy and corresponding elemental mappings of $\mathrm{C}, \mathrm{O}, \mathrm{N}$ and $\mathrm{Co}$.

The morphologies and nanostructures of the samples prepared in this study are characterized by using SEM and TEM. Figure 5a displays some rhombic dodecahedrons which belong to ZIF-67 polyhedron, and the average diameter of ZIF-67 polyhedron is about $300 \mathrm{~nm}$. SEM image of the porous $\mathrm{Co} / \mathrm{C}$ composites which prepared by the calcination of ZIF-67 precursors is presented in Figure 5b. The corresponding TEM images with different magnification are also presented in Figure $5 \mathrm{~d}$,e. It can be observed from Figure $5 b$ that the composites still possess a rhombic dodecahedral shape after calcination process, while the average diameter shows an obvious decline from $\sim 230 \mathrm{~nm}$ to $\sim 180 \mathrm{~nm}$. This is because the high temperature consumes the organic components, leading the crystals shrink to a large extent and exhibit a sunken surface. Co/C@PPy with chain-like structure is identifiable from Figure 5c,f. Especially, XRD pattern presented in Figure S1 shows that the intensities of the diffraction of $\mathrm{Co}$ or $\mathrm{CoO}$ are greatly reduced owing to the presence of PPy with its amorphous nature. This interesting phenomenon is consistent with the morphology presented in Figure 5e, the detailed morphology of Co/C can hardly be observed because of the heavy PPy coating. 

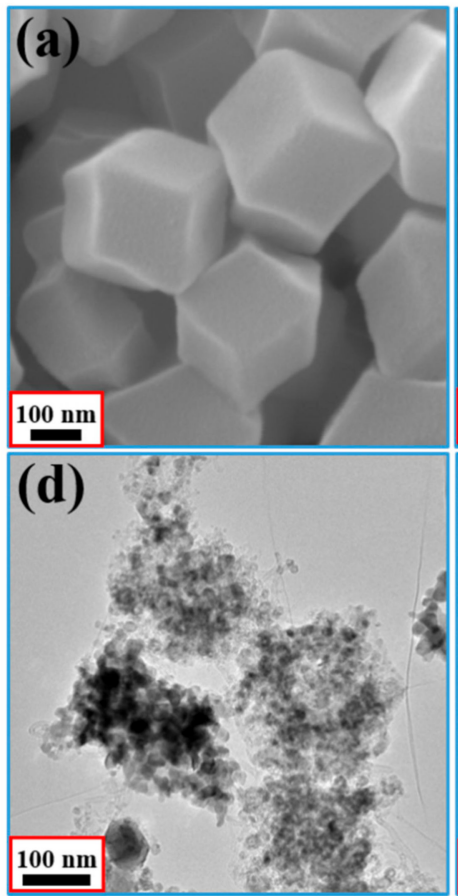
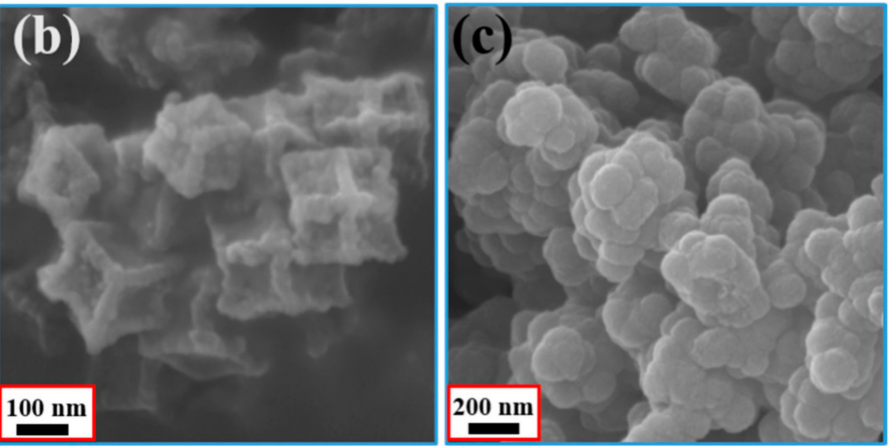

(e)
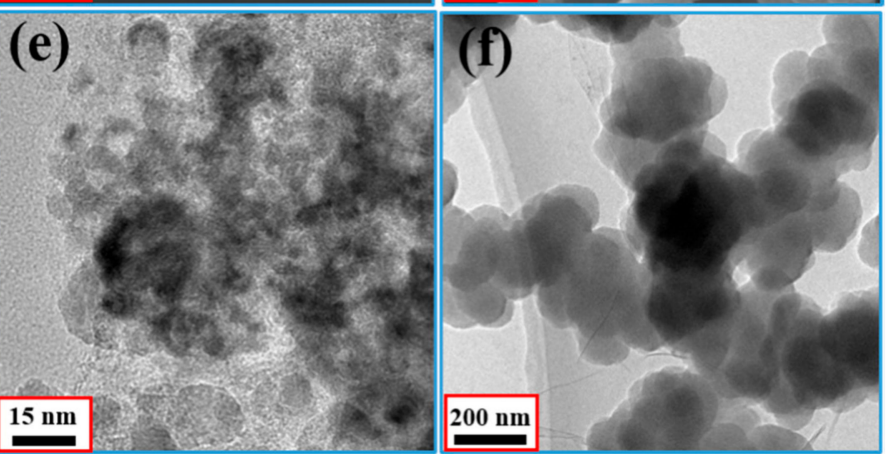

Figure 5. SEM images of ZIF-67 (a); Co/C (b) and Co/C@PPy (c); TEM images of Co/C (d,e); and Co/C@PPy (f).

\subsection{Electromagnetic Absorption Property}

Electromagnetic attributes $\left(\mu_{r}\right.$ and $\left.\varepsilon_{r}\right)$ of Co/C and Co/C@PPy loaded various filler are tested and shown in Figure 6. Generally speaking, the real parts of the electromagnetic attributes $\left(\varepsilon^{\prime}, \mu^{\prime}\right)$ are correlated with the amount of polarization in the composite and represent the storage ability of the electric and magnetic energy. While the imaginary parts $\left(\varepsilon^{\prime \prime}, \mu^{\prime \prime}\right)$ denote the dissipated electric and magnetic energies. Because of the rare ratio of the magnetic constituents in these samples, the values of $\mu^{\prime}$ and $\mu^{\prime \prime}$ are approximately constant $\left(\mu^{\prime} \approx 1.0\right.$ and $\left.\mu^{\prime \prime} \approx 0\right)$ with a slight fluctuation, and it is suggested that all these samples belong to dielectric loss absorbers. Generally, in the frequency range of microwaves, dielectric loss mainly derives from the dipolar polarization and interfacial polarization. In this work, the dipolar polarization can be originated from carbon and PPy aerogel, while the interfacial polarization mainly provided by the the heterostructure constructed by ternary components. Based on the equation $\varepsilon^{\prime}=\varepsilon^{\prime \prime} / 2 \pi f+\varepsilon_{\infty}$ [5], the variation trend of $\varepsilon^{\prime}$ remains similar to that of $\varepsilon^{\prime \prime}$. As shown in Figure 6, all the samples present typical frequency dependent permittivity. Specifically, the values of $\varepsilon^{\prime}$ decrease with the increasing frequency which mainly result from the fact that in the high $\mathrm{GHz}$ frequency region, the dielectric polarization fails to catch up with the variable electromagnetic field. With the increase of Co/C loading (from $15 \mathrm{wt} \%$ to $45 \mathrm{wt} \%$ ), significant enhancements are achieved in both $\varepsilon^{\prime}$ and $\varepsilon^{\prime \prime}$ (Figure 6a-c). The increment of $\varepsilon^{\prime}$ can be attributed to the sufficient conductive interconnections. Besides, the enhanced storage capability and dissipation ability are also indicated. However, it is known that a proper value of permittivity is beneficial for impedance matching. Note that the addition of PPy (Co/C@PPy) noticeably improves the permittivity. The conductive interconnections could be established even in an extremely low filler loading ratio (Figure 6d), which may indicate the dielectric property of $\mathrm{Co} / \mathrm{C}$ are highly enhanced by the PPy aerogel. 
(a)

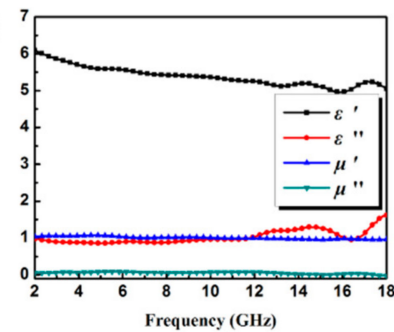

(d)

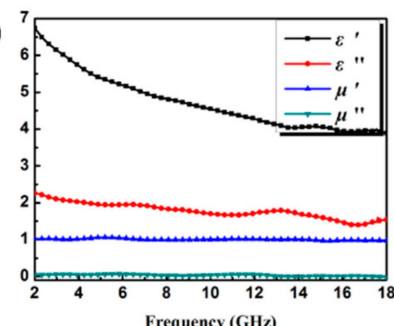

(g)

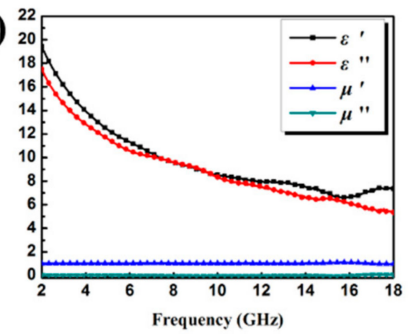

(b)

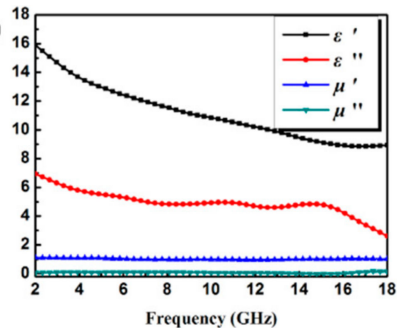

(e)

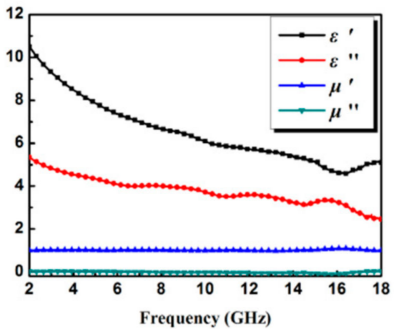

(h)

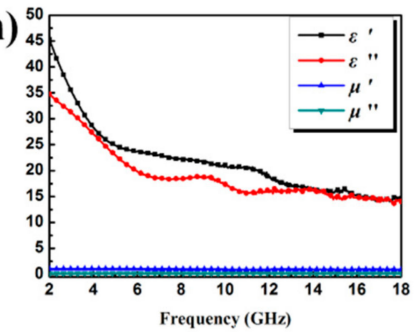

(c)

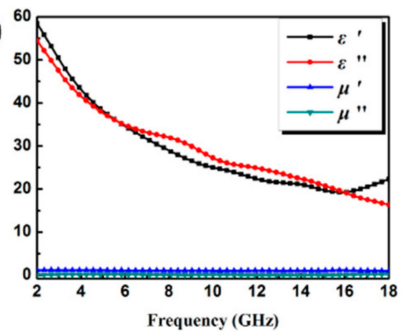

(f)

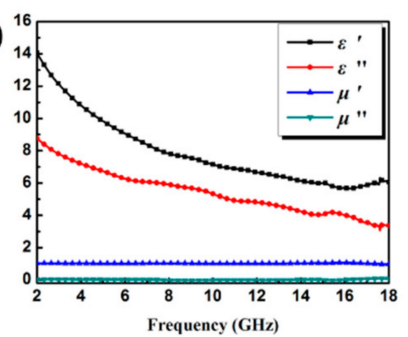

Figure 6. Frequency dependence of real and imaginary parts of complex permittivity and permeability of $\mathrm{Co} / \mathrm{C}$ with the filler loading of $15 \mathrm{wt} \%$ (a), $30 \mathrm{wt} \%$ (b), $45 \mathrm{wt} \%$ (c); and Co/C@PPy with the filler loading of $5 \mathrm{wt} \%$ (d), $10 \mathrm{wt} \%$ (e), $12 \mathrm{wt} \%$ (f), $15 \mathrm{wt} \%$ (g), $30 \mathrm{wt} \%$ (h).

Figure $7 \mathrm{a}-\mathrm{c}$ depicts the simulated reflection loss (RL) curves obtained for $\mathrm{Co} / \mathrm{C}$ paraffin composites with Co/C loading of $15-45 \mathrm{wt} \%$ at various thickness $(1.5-4 \mathrm{~mm})$. Note that the $30 \mathrm{wt} \%$ $\mathrm{Co} / \mathrm{C}$ paraffin composite exhibits the best EA performance. Specifically, the minimum RL of $-24.98 \mathrm{~dB}$ is achieved at $16.96 \mathrm{GHz}$ with the thickness of $1.5 \mathrm{~mm}$. The broadest effective bandwidth can reach $4.4 \mathrm{GHz}(10.08-14.48 \mathrm{GHz})$ when the thickness is $2.0 \mathrm{~mm}$. In the low filler loading (15 wt \%). Because of the high dispersion of the $\mathrm{Co} / \mathrm{C}$ composite in the paraffin matrix, the conductive interconnections can hardly be formed. While in the high filler loading ( $45 \mathrm{wt} \%)$ condition, the extremely high values of $\varepsilon^{\prime}$ and $\varepsilon^{\prime \prime}$ cause the impedance mismatch and thus lead the electromagnetic wave reflect on the surface rather than absorption. The aforementioned reasons may explain the bad EA performance. Obviously, the EA properties of Co/C@PPy are substantially enhanced relative to the pristine Co/C. It can also be found that a higher concentration in this material leads to opposite EA performance. As shown in Figure 7d, the Co/C@PPy composite with a loading of only $5 \mathrm{wt} \%$ even shows a strong absorption both in intensity and bandwidth. The optimal RL is up to $-17.85 \mathrm{~dB}$ at $12.92 \mathrm{GHz}$ with the thickness of $3.0 \mathrm{~mm}$, corresponding to an effective bandwidth of $5.2 \mathrm{GHz}(10.84-16.04 \mathrm{GHz})$. It is rare to find other reported materials which can exhibit such a broad EA bandwidth under this extreme filler loading. Furthermore, when the filler loading is up to $10 \mathrm{wt} \%$ (Figure 7e), more Co/C@PPy molecules connect with each other and an efficient conductive network is formed. In addition, the proper complex permittivity also leads a better impedance match. The optimal RL value of $-44.76 \mathrm{~dB}$ can be achieved at $17.32 \mathrm{GHz}$ with the thickness of $2.0 \mathrm{~mm}$. A considerable broad effective bandwidth of $6.56 \mathrm{GHz}$ $(11.04-17.60 \mathrm{GHz}$ ) is reached with the thickness of $2.5 \mathrm{~mm}$ (As shown in Figure 7g). The result can fully demonstrate that the as-prepared Co/C@PPy is much more efficient than that of most other ZIF-67 derived $\mathrm{Co} / \mathrm{C}$ composites or their hybrids. Herein, take the work presented by Lü et al. [25] as an example, the exhibited maximum reflection loss of $\mathrm{Co} / \mathrm{C}-500$ can reach $-35.3 \mathrm{~dB}$ at $5.8 \mathrm{GHz}$ with 
a thickness of $4 \mathrm{~mm}$, the effective absorption bandwidth is $5.80 \mathrm{GHz}$ with a thickness of $2.5 \mathrm{~mm}$, and the corresponding filler loading ratio is as large as $40 \mathrm{wt} \%$. By comparison, the as-prepared Co/C@PPy has advantages in intensity, bandwidth, matching thickness, as well as efficient filler loading. The excellent EA performance of Co/C@PPy may be attributed to the following fact. First, the unique chain-like $\mathrm{PPy}$ aerogel and the porous feature of $\mathrm{Co} / \mathrm{C}$ itself can induce more multiple reflection and diffuse scattering of the incident electromagnetic wave. Second, the multi-interfaces between Co/C and PPy would induce interfacial polarization, are equally important for the attenuation.
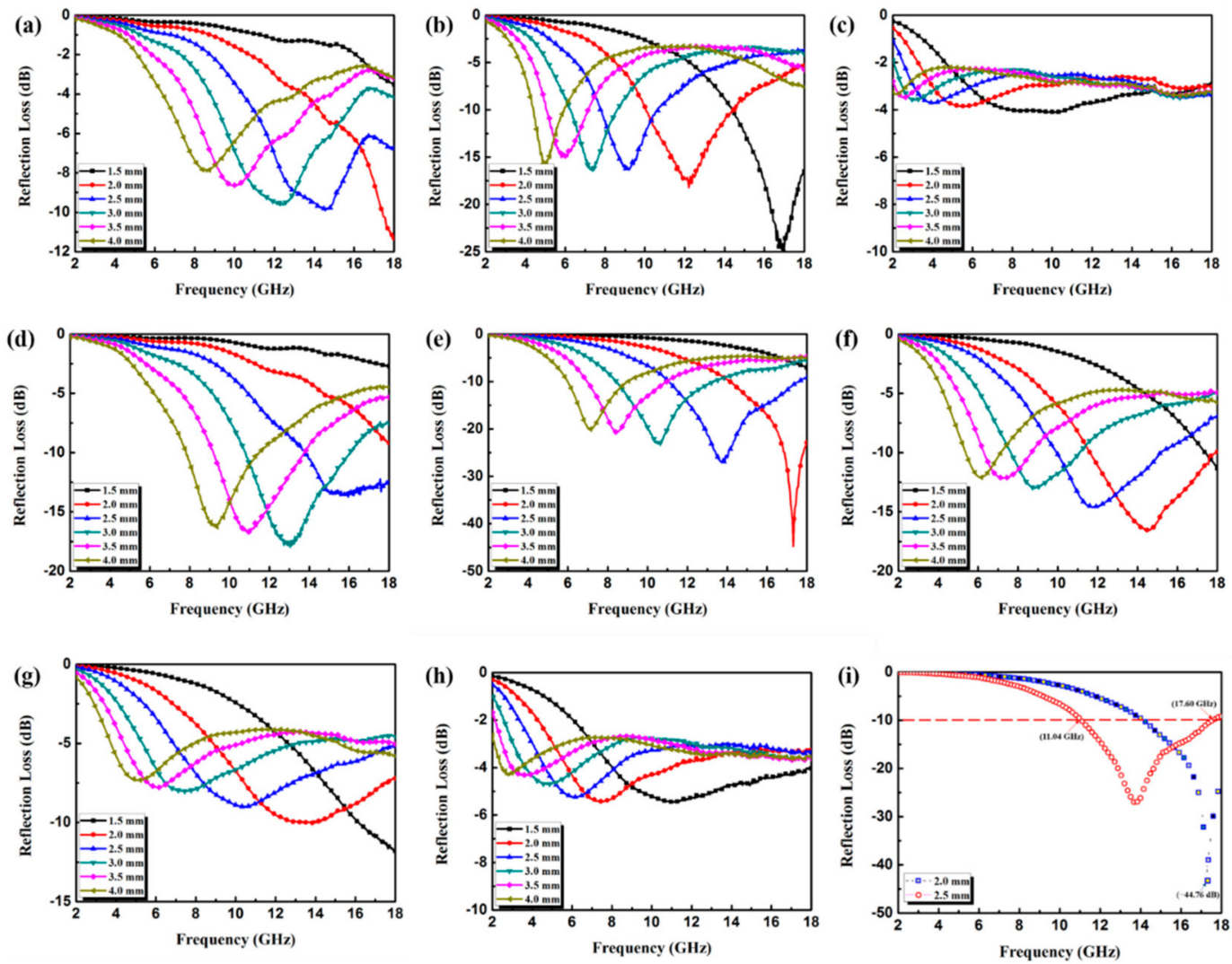

Figure 7. Reflection loss curves of paraffin composites containing $15 \mathrm{wt} \%$ (a), $30 \mathrm{wt} \%$ (b), and $45 \mathrm{wt} \%$ (c) Co/C, respectively; reflection loss curves of paraffin composites containing $5 \mathrm{wt} \%$ (d), $10 \mathrm{wt} \%$ (e), 12 wt \% (f), 15 wt \% (g), and 30 wt \% (h) Co/C@PPy, respectively; Reflection loss curves of paraffin composites containing $10 \mathrm{wt} \%$ (i) under the thickness of $2.0 \mathrm{~mm}$ and $2.5 \mathrm{~mm}$. The testing frequency range is from 2 to $18 \mathrm{GHz}$.

One phenomenon can be observed that all the samples achieve the minimum RL value at a certain thickness, and all their RL peaks shift to lower frequency with the increasing thickness. To illustrate why the RL peaks appear at these certain thicknesses, the simulations of the matching thickness versus the achieved peaks frequency are completed based on the equation: $t_{\mathrm{m}}=n c /\left(4 f_{\mathrm{m}} \sqrt{\left|\varepsilon_{r}\right|\left|\mu_{r}\right|}\right)$ [22] . When the matching thickness satisfies the equation, then the reflected wave and incident wave will be out of opposite phase, resulting in the dissipation at the interface. In Figure 8, the 2D contour maps of reflection loss of the paraffin composites containing different loading ratio of Co/C@PPy as well as the corresponding calculated curves of $t_{\mathrm{m}}$ according $\lambda / 4$ condition are plotted. The points of the minimum RL lie on the curves of $t_{\mathrm{m}}$ for each sample. So the result demonstrates that the EA activities of the as-prepared samples obey the quarter-wavelength principle. 

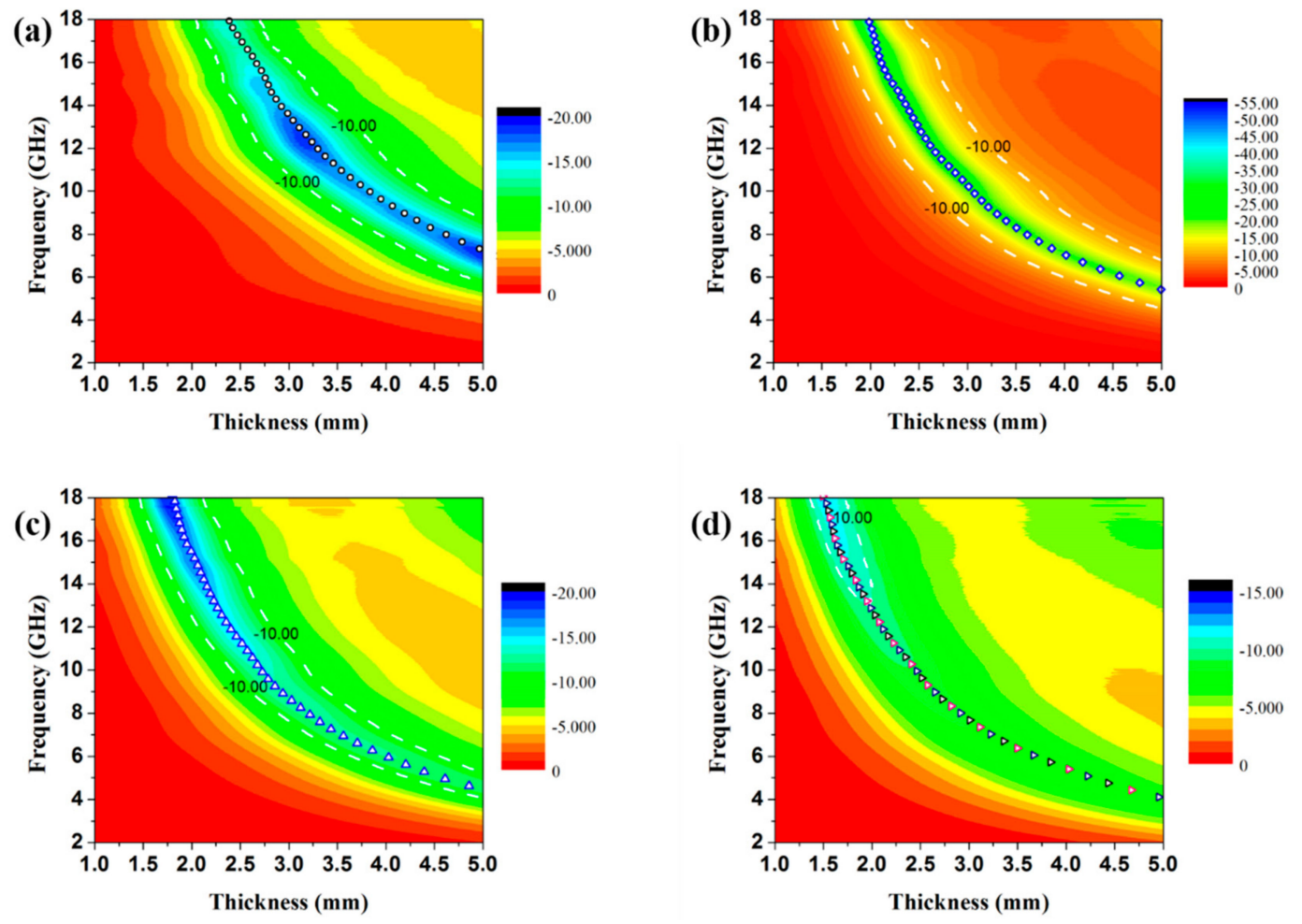

Figure 8. Contour maps of reflection loss of the paraffin composites containing $5 \mathrm{wt} \%$ (a), $10 \mathrm{wt} \%$ (b), $12 \mathrm{wt} \%$ (c), and $15 \mathrm{wt} \%$ (d) Co/C@PPy and the calculated curves of $t_{\mathrm{m}}$ according $\lambda / 4$ model, respectively. The testing frequency range is from 2 to $18 \mathrm{GHz}$. (white line: region of $-10 \mathrm{~dB}$ ).

Generally, impedance matching ratio $Z$ calculated by $Z=Z_{\text {in }} / Z_{0}$ can reveal the degree of impedance matching. If $Z=1$, namely the incident wave can enter into the composite entirely with zero-reflection on the surface [39]. A higher $Z$ value implies the preferable EA property. In addition, the energy attenuation should also be taken into account. The attenuation constant $(\alpha)$ can be expressed as [8]

$$
\alpha=\frac{\sqrt{2} \pi f}{c} \times \sqrt{\left(\mu^{\prime \prime} \varepsilon^{\prime \prime}-\mu^{\prime} \varepsilon^{\prime}\right)+\sqrt{\left(\mu^{\prime \prime} \varepsilon^{\prime \prime}-\mu^{\prime} \varepsilon^{\prime}\right)^{2}+\left(\mu^{\prime} \varepsilon^{\prime \prime}+\mu^{\prime \prime} \varepsilon^{\prime}\right)^{2}}}
$$

where $c$ is the velocity of light in a vacuum. In Figure 9, the calculated impedance matching ratio $(Z)$ and the attenuation constant $(\alpha)$ for paraffin composites containing different loading ratio of Co/C@PPy are plotted. An excellent absorber should consider both attenuation ability and impedance matching at the same time rather than unilateral superior performance. From Figure 9, it can be found that the composite loaded with $10 \mathrm{wt} \%$ has the high $\mathrm{Z}$ value as well as a suitable attenuation constant, which are in favorable for the enhancement of EA property. Table S1 shows the EA properties of some recently reported carbon derived-MOF or PPy based composites. In comparison with these composites, the chain-like structured Co/C@PPy takes the advantages in the bandwidth and intensity. Furthermore, the extremely low filler loadings (only $5 \mathrm{wt} \%$ and $10 \mathrm{wt} \%$ ) make Co/C@PPy more competitive in application. The excellent EA property of the as-prepare Co/C@PPy mainly benefit from its moderate impedance matching, strong attenuation capacity, as well as the multiple reflection induced by the unique structure. 

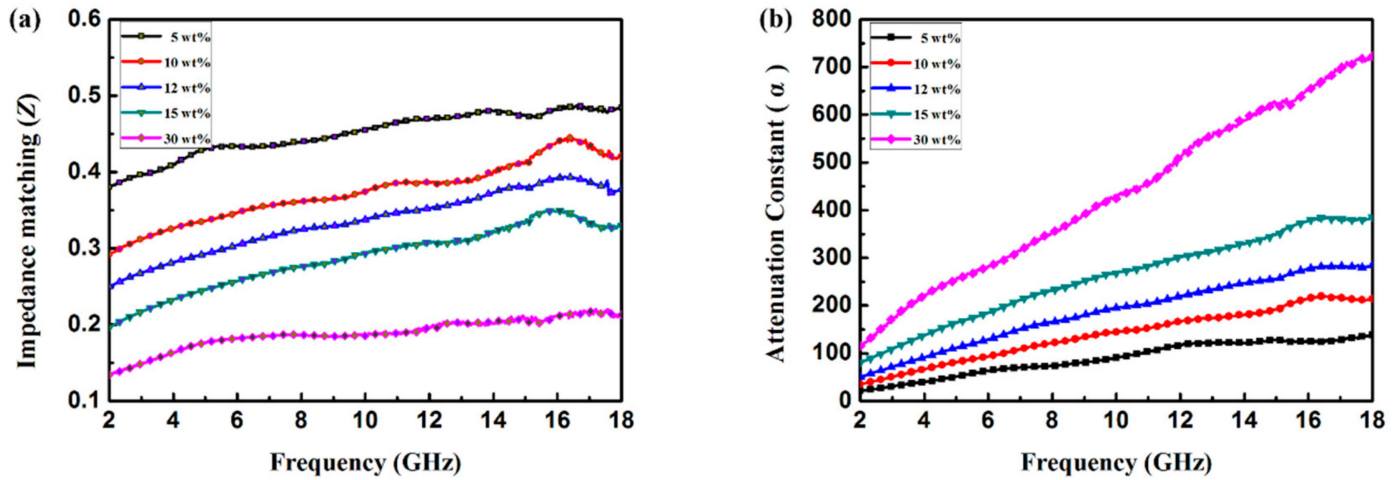

Figure 9. Frequency dependence of impedance matching ratio (a) and attenuation constant (b) for paraffin composites containing different loading ratio of Co/C@PPy.

\section{Conclusions}

In summary, a chain-like structured PPy aerogel decorated with MOF-derived nanoporous Co/C (Co/C@PPy) has been successfully prepared and its EA property was firstly investigated. In the unique ternary composite, the additional interfaces can induce the interfacial polarization, which further contributes to the reflection loss. Compared to pristine MOF-derived nanoporous Co/C, Co/C@PPy exhibits substantially enhancement with high intensity and broad width at a low thickness and an extremely low filler loading. The composite loaded with $10 \mathrm{wt} \% \mathrm{Co} / \mathrm{C} @ \mathrm{PPy}$ can reach the optimal RL value of $-44.76 \mathrm{~dB}$ at $17.32 \mathrm{GHz}$ with the thickness of $2.0 \mathrm{~mm}$. A considerable broad effective bandwidth of $6.56 \mathrm{GHz}(11.04-17.60 \mathrm{GHz})$ is achieved with the thickness of $2.5 \mathrm{~mm}$. A composite only load with $5 \mathrm{wt} \% \mathrm{Co} / \mathrm{C} @ \mathrm{PPy}$ also shows an effective EA bandwidth of $5.20 \mathrm{GHz}$, which is even better than numerous reported EA materials. The outstanding performance can be attributed to a proper impedance matching and a high dielectric loss. Besides, the unique chain-like PPy aerogel and the porous feature of $\mathrm{Co} / \mathrm{C}$ itself can induce more multiple reflection and scattering of the incident electromagnetic wave, and are equally important for the attenuation. Therefore, it is believed that the Co/C@PPy aerogel with high absorption intensity, broad bandwidth, and light weight can be utilized as a competitive absorber.

Supplementary Materials: The following are available online at http:/ / www.mdpi.com/1996-1944/11/5/781/s1, Figure S1: XRD patterns of Co/C@PPy, Figure S2: Elemental mappings of $C$ and $C$ o for $\mathrm{Co} / \mathrm{C}$ composites, Figure S3: TG curves of ZIF-67 under air and Ar atmosphere, Table S1: EA performance of typical MOF-derived Co/C or PPy based composites reported in this work and recent literatures.

Author Contributions: X.S. conceived and designed the experiments; X.L. and X.L. performed the experiments; M.S. and X.W. analyzed the data; X.S. and J.W. wrote the paper.

Funding: This project was financially supported by the National Key Research and Development Program (2016YFA0202900).

Conflicts of Interest: The authors declare no conflict of interest.

\section{References}

1. Zhang, X.; Ji, G.; Liu, W.; Quan, B.; Liang, X.; Shang, C.; Cheng, Y.; Du, Y. Thermal conversion of an $\mathrm{Fe}_{3} \mathrm{O}_{4} @$ metal-organic framework: A new method for an efficient Fe-Co/nanoporous carbon microwave absorbing material. Nanoscale 2015, 7, 12932-12942. [CrossRef] [PubMed]

2. Xie, A.; Sun, M.; Zhang, K.; Jiang, W.; Wu, F.; He, M. In situ growth of $\mathrm{MoS}_{2}$ nanosheets on reduced graphene oxide (RGO) surfaces: Interfacial enhancement of absorbing performance against electromagnetic pollution. Phys. Chem. Chem. Phys. 2016, 18, 24931-24936. [CrossRef] [PubMed]

3. Yu, M.; Liang, C.; Liu, M.; Liu, X.; Yuan, K.; Cao, H.; Che, R. Yolk-shell $\mathrm{Fe}_{3} \mathrm{O}_{4} @ \mathrm{ZrO}_{2}$ prepared by a tunable polymer surfactant assisted sol-gel method for high temperature stable microwave absorption. J. Mater. Chem. C 2014, 2, 7275-7283. [CrossRef] 
4. Chen, Y.; Huang, Z.; Lu, M.; Cao, W.; Yuan, J.; Zhang, D.; Cao, M. 3D Fe $\mathrm{O}_{4}$ nanocrystals decorating carbon nanotubes to tune electromagnetic properties and enhance microwave absorption capacity. J. Mater. Chem. A 2015, 3, 2621-12625. [CrossRef]

5. Zhang, Y.; Quan, B.; Liu, W.; Liang, X.; Ji, G.; Du, Y. A facile one-pot strategy for fabrication of carbon-based microwave absorbers: Effects on annealing and paraffin content. Dalton Trans. 2017, 46, 9097-9102. [CrossRef] [PubMed]

6. Liu, P.; Huang, Y.; Yan, J.; Yang, Y.; Zhao, Y. Construction of CuS Nanoflakes Vertically Aligned on Magnetically Decorated Graphene and Their Enhanced Microwave Absorption Properties. ACS Appl. Mater. Interfaces 2016, 8, 5536-5546. [CrossRef] [PubMed]

7. Chen, J.; Liu, M.; Yang, T.; Zhai, F.; Hou, X.; Chou, K. Improved microwave absorption performance of modified $\mathrm{SiC}$ in the 2-18 GHz frequency range. CrystEngComm 2017, 19, 519-527. [CrossRef]

8. Zhao, B.; Shao, G.; Fan, B.; Guo, W.; Xie, Y.; Zhang, R. Facile synthesis of Ni/ZnO composite: Morphology control and microwave absorption properties. J. Magn. Magn. Mater. 2015, 382, 78-83. [CrossRef]

9. Zhang, Y.; Liu, Y.; Wang, X.; Yuan, Y.; Lai, W.; Wang, Z.; Zhang, X.; Liu, X. Towards efficient microwave absorption: Intrinsic heterostructure of fluorinated SWCNTs. J. Mater. Chem. C 2017, 5, 11847-11855. [CrossRef]

10. Wu, F.; Sun, M.; Jiang, W.; Zhang, K.; Xie, A.; Wang, Y.; Wang, M. A self-assembly method for the fabrication of a three-dimensional (3D) polypyrrole (PPy)/poly(3,4-ethylenedioxythiophene) (PEDOT) hybrid composite with excellent absorption performance against electromagnetic pollution. J. Mater. Chem. C 2016, 4, 82-88. [CrossRef]

11. Quan, B.; Liang, X.; Ji, G.; Ma, J.; Ouyang, P.; Gong, H.; Xu, G.; Du, Y. Strong Electromagnetic Wave Response Derived from the Construction of Dielectric/Magnetic Media Heterostructure and Multiple Interfaces. ACS Appl. Mater. Interfaces 2017, 9, 9964-9974. [CrossRef] [PubMed]

12. Wu, F.; Xie, A.; Sun, M.; Wang, Y.; Wang, M. Reduced graphene oxide (RGO) modified spongelike polypyrrole (PPy) aerogel for excellent electromagnetic absorption. J. Mater. Chem. A 2015, 3, 14358-14369. [CrossRef]

13. Zhang, W.; Sun, Y.; Xiao, Z.; Li, W.; Li, B.; Huang, X.; Liu, X.; Hu, J. Heterostructures of CuS nanoparticle/ $\mathrm{ZnO}$ nanorod arrays on carbon fibers with improved visible and solar light photocatalytic properties. J. Mater. Chem. A 2015, 3, 7304-7313. [CrossRef]

14. Zhao, B.; Shao, G.; Fan, B.; Zhao, W.; Xie, Y.; Zhang, R. Synthesis of flower-like CuS hollow microspheres based on nanoflakes self-assembly and their microwave absorption properties. J. Mater. Chem. A 2015, 3, 10345-10352. [CrossRef]

15. Hu, Q.; Qi, X.; Cai, H.; Xie, R.; Long, L.; Bai, Z.; Jiang, Y.; Qin, S.; Zhong, W.; Du, Y. Preparation of porous $\mathrm{Fe}_{2} \mathrm{O}_{3}$ nanorods-reduced graphene oxide nanohybrids and their excellent microwave absorption properties. Sci. Rep. 2017, 7, 11213. [CrossRef] [PubMed]

16. Zhang, Z.; Liu, X.; Wang, X.; Wu, Y.; Liu, Y. Electromagnetic and microwave absorption properties of $\mathrm{Fe} \mathrm{Sr}_{0.8} \mathrm{La}_{0.2} \mathrm{Fe}_{11.8} \mathrm{Co}_{0.2} \mathrm{O}_{19}$ shell-core composites. J. Magn. Magn. Mater. 2012, 324, 2177-2182. [CrossRef]

17. Peng, C.; Wang, H.; Kan, S.; Shen, M.; Wei, Y.; Chen, S. Microwave absorbing materials using Ag-NiZn ferrite core-shell nanopowders as fillers. J. Magn. Magn. Mater. 2004, 284, 113-119. [CrossRef]

18. Zheng, J.; Yu, Z.; Ji, G.; Lin, X.; Lv, H.; Du, Y. Reduction synthesis of $\mathrm{Fe}_{\mathrm{x}} \mathrm{O}_{\mathrm{y}} @ \mathrm{SiO}_{2}$ core-shell nanostructure with enhanced microwave-absorption properties. J. Alloys Compd. 2014, 602, 8-15. [CrossRef]

19. Xie, A.; Wu, F.; Jiang, W.; Zhang, K.; Sun, M.; Wang, M. Chiral induced synthesis of helical polypyrrole (PPy) nano-structures: A lightweight and high-performance material against electromagnetic pollution. J. Mater. Chem. C 2017, 5, 2175-2181. [CrossRef]

20. Jiang, W.; Sun, M.; Zhang, K.; Wu, F.; Xie, A.; Wang, M. Three-dimensional (3D) $\alpha-\mathrm{Fe}_{2} \mathrm{O}_{3} /$ polypyrrole (PPy) nanocomposite for effective electromagnetic absorption. AIP Adv. 2016, 6, 065021. [CrossRef]

21. Li, B.; Weng, X.; Wu, G.; Zhang, Y.; Lv, X.; Gu, G. Synthesis of $\mathrm{Fe}_{3} \mathrm{O}_{4}$ /polypyrrole/polyaniline nanocomposites by in-situ method and their electromagnetic absorbing properties. J. Saudi Chem. Soc. 2017, 21, 466-472. [CrossRef]

22. Sui, M.; Lü, X.; Xie, A.; Xu, W.; Rong, X.; Wu, G. The synthesis of three-dimensional (3D) polydopamine-functioned carbonyl iron powder@polypyrrole (CIP@PPy) aerogel composites for excellent microwave absorption. Synth. Met. 2015, 210, 156-164. [CrossRef] 
23. Jiang, W.; Sun, M.; Zhang, K.; Dai, X.; Xia, Y.; Wang, D.; Xie, A.; Wu, F. Using $\gamma-\mathrm{Fe}_{2} \mathrm{O}_{3}$ to tune the electromagnetic properties of three-dimensional (3D) polypyrrole (PPy) and its broadband electromagnetic absorber. RSC Adv. 2016, 6, 68128-68133. [CrossRef]

24. Zhang, K.; Sun, M.; Jiang, W.; Wang, Y.; Wang, D.; Wu, F.; Xie, A.; Dong, W. A core-shell polypyrrole@silicon carbide nanowire (PPy@SiC) nanocomposite for the broadband elimination of electromagnetic pollution. RSC Adv. 2016, 6, 43056-43059. [CrossRef]

25. Lü, Y.; Wang, Y.; Li, H.; Lin, Y.; Jiang, Z.; Xie, Z.; Kuang, Q.; Zheng, L. MOF-Derived Porous Co/C Nanocomposites with Excellent Electromagnetic Wave Absorption Properties. ACS Appl. Mater. Interfaces 2015, 7, 13604-13611. [CrossRef] [PubMed]

26. Liang, X.; Quan, B.; Ji, G.; Liu, W.; Cheng, Y.; Zhang, B.; Du, Y. Novel nanoporous carbon derived from metal-organic frameworks with tunable electromagnetic wave absorption capabilities. Inorg. Chem. Front. 2016, 3, 1516-1526. [CrossRef]

27. Wang, H.; Wang, Y.; Jia, A.; Wang, C.; Wu, L.; Yang, Y.; Wang, Y. A novel bifunctional Pd-ZIF-8/rGO catalyst with spatially separated active sites for the tandem Knoevenagel condensation-reduction reaction. Catal. Sci. Technol. 2017, 7, 5572-5584. [CrossRef]

28. Tian, T.; Wharmby, M.T.; Parra, J.B.; Ania, C.O.; Fairen-Jimenez, D. Role of crystal size on swing-effect and adsorption induced structure transition of ZIF-8. Dalton Trans. 2016, 45, 6893-6900. [CrossRef] [PubMed]

29. Falcaro, P.; Ricco, R.; Doherty, C.M.; Liang, K.; Hill, A.J.; Styles, M.J. MOF positioning technology and device fabrication. Chem. Soc. Rev. 2014, 43, 5513-5560. [CrossRef] [PubMed]

30. Wei, J.; Hu, Y.; Wu, Z.; Liang, Y.; Leong, S.; Kong, B.; Zhang, X.; Zhao, D.; Simon, G.P.; Wang, H. Mesoporous nanostructured $\mathrm{Co}_{3} \mathrm{O}_{4}$ derived from MOF template: A high-performance anode material for lithium-ion batteries. J. Mater. Chem. A 2015, 3, 16867-16873. [CrossRef]

31. Li, C.; Chen, T.; Xu, W.; Lou, X.; Pan, L.; Chen, Q.; Hu, B. A graphene-directed assembly route to hierarchically porous Co-Nx/C catalysts for high-performance oxygen reduction. J. Mater. Chem. A 2015, 3, 5585-5591. [CrossRef]

32. Salunkhe, R.R.; Kamachi, Y.; Torad, N.L.; Hwang, S.M.; Sun, Z.; Dou, S.X.; Kim, J.H.; Yamauchi, Y. Fabrication of symmetric supercapacitors based on MOF-derived nanoporous carbons. J. Mater. Chem. A 2014, 2, 19848-19854. [CrossRef]

33. Yuan, J.; Liu, Q.; Li, S.; Lu, Y.; Jin, S.; Li, K.; Chen, H.; Zhang, H. Metal organic framework (MOF)-derived carbonaceous $\mathrm{Co}_{3} \mathrm{O}_{4} / \mathrm{Co}$ microframes anchored on RGO with enhanced electromagnetic wave absorption performances. Synth. Met. 2017, 228, 32-40. [CrossRef]

34. Qiang, R.; Du, Y.; Chen, D.; Ma, W.; Wang, Y.; Xu, P.; Ma, J.; Zhao, H.; Han, X. Electromagnetic functionalized $\mathrm{Co} / \mathrm{C}$ composites by in situ pyrolysis of metal-organic frameworks (ZIF-67). J. Alloys Compd. 2016, 681, 384-393. [CrossRef]

35. Jian, X.; Chen, X.; Zhou, Z.; Li, G.; Jiang, M.; Xu, X.; Lu, J.; Li, Q.; Wang, Y.; Gou, J.; et al. Remarkable improvement in microwave absorption by cloaking a micro-scaled tetrapod hollow with helical carbon nanofibers. Phys. Chem. Chem. Phys. 2015, 17, 3024-3031. [CrossRef] [PubMed]

36. Arief, I.; Biswas, S.; Bose, S. FeCo-Anchored Reduced Graphene Oxide Framework-Based Soft Composites Containing Carbon Nanotubes as Highly Efficient Microwave Absorbers with Excellent Heat Dissipation Ability. ACS Appl. Mater. Interfaces 2017, 9, 19202-19214. [CrossRef] [PubMed]

37. Sano, E.; Akiba, E. Electromagnetic absorbing materials using nonwoven fabrics coated with multi-walled carbon nanotubes. Carbon 2014, 78, 463-468. [CrossRef]

38. Yan, P.; Miao, J.; Cao, J.; Zhang, H.; Wang, C.; Xie, A.; Shen, Y. Facile synthesis and excellent electromagnetic wave absorption properties of flower-like porous RGO/PANI/ $\mathrm{Cu}_{2} \mathrm{O}$ nanocomposites. J. Mater. Sci. 2017, 52, 13078-13090. [CrossRef]

39. Li, D.; Zhang, B.; Liu, W.; Liang, X.; Ji, G. Tailoring the input impedance of FeCo/C composites with efficient broadband absorption. Dalton Trans. 2017, 46, 14926-14933. [CrossRef] [PubMed]

40. Pan, Y.; Wang, G.; Yue, Y. Fabrication of $\mathrm{Fe}_{3} \mathrm{O}_{4} @ \mathrm{SiO}_{2} @ \mathrm{RGO}$ nanocomposites and their excellent absorption properties with low filler content. RSC Adv. 2015, 5, 71718-71723. [CrossRef]

(C) 2018 by the authors. Licensee MDPI, Basel, Switzerland. This article is an open access article distributed under the terms and conditions of the Creative Commons Attribution (CC BY) license (http:/ / creativecommons.org/licenses/by/4.0/). 